\title{
Equilibrium Melting Temperature of Poly(ferrocenyl dimethylsilane) in Homopolymers and Lamellar Diblock Copolymers with Polystyrene ${ }^{\mathrm{a}}$
}

\author{
Jianjun Xu, Vasilios Bellas, Bernd Jungnickel, Bernd Stühn, \\ Matthias Rehahn*
}

The equilibrium melting temperature, $T_{\mathrm{m}, 0}$, of poly(ferrocenyl dimethylsilane) (PFDMS) is reinvestigated using two PFDMS homopolymers and a PS-b-PFDMS copolymer (PS: polystyrene). The melting temperatures of samples crystallized at different crystallization temperatures, $T_{\mathrm{c}}$, were found to depend in a nonlinear fashion on $T_{\mathrm{c}}$. Consequently, the Hoffmann-Weeks approach fails in determining $T_{\mathrm{m}, 0}$. The more reliable Gibbs-Thomson approach results in a $T_{\mathrm{m}, 0}=$ $(215 \pm 11){ }^{\circ} \mathrm{C}$ for the PFDMS homopolymers, and a $T_{\mathrm{m}, 0}=(179 \pm 5)^{\circ} \mathrm{C}$ for the PFDMS microphases in the lamellar PS-b-PFDMS diblock copolymer.
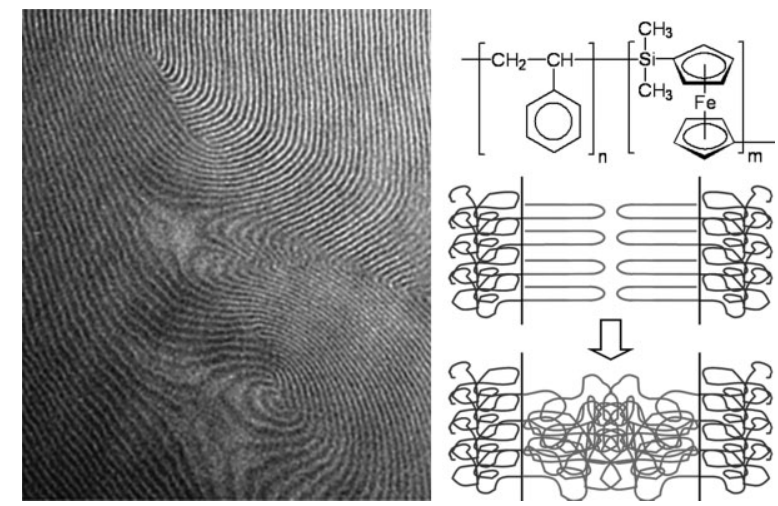

\section{Introduction}

The metal-containing polymer poly(ferrocenyl dimethylsilane) (PFDMS) is currently attracting much attention because of its promising optoelectronic and redox proper-

\section{J. Xu, V. Bellas, M. Rehahn}

Ernst-Berl-Institut für Technische und Makromolekulare Chemie, Technische Universität Darmstadt, Petersenstrasse 22, D-64287 Darmstadt, Germany

E-mail: mrehahn@dki.tu-darmstadt.de

B. Jungnickel, B. Stühn

Institut für Festkörperphysik, Technische Universität Darmstadt, Hochschulstrasse 6, D-64289 Darmstadt, Germany

J. Xu, B. Jungnickel, M. Rehahn

Deutsches Kunststoff-Institut (DKI), Schlossgartenstrasse 6,

D-64289 Darmstadt, Germany

\footnotetext{
a This article is related to the Special Issue "Metal-Containing and Metallo-Supramolecular Polymers and Materials" guest-edited by U. Schubert in Macromolecular Rapid Communications.
}

ties, and because it represents a valuable precursor for ceramics and magnetic materials. ${ }^{[1-7]}$ Moreover, it counts among the very few metallopolymers accessible by living chain-growth protocols which give access not only to products of defined molar mass and narrow polydispersity but also to a broad variety of copolymer architectures: plenty of PFDMS block copolymers with, e.g., polystyrene (PS), ${ }^{[8-11]}$ polyisoprene (PI), ${ }^{[12]}$ poly(dimethyl siloxane) (PDMS), ${ }^{[8,12,13]}$ poly(ethylene oxide) (PEO), ${ }^{[14]}$ poly(methyl methacrylate) (PMMA), ${ }^{[15-21]}$ and poly(2-vinylpyridine) ${ }^{[22]}$ have been synthesized, and they have been shown to develop fascinating morphologies at the nanometer to micrometer scale. ${ }^{[2,7,23]}$ Another important feature of PFDMS is its ability to crystallize. ${ }^{[24]}$ It exhibits a $T_{\mathrm{g}}$ of around $30^{\circ} \mathrm{C}$ and-depending on molecular mass and thermal history $-\mathrm{a}$ melting temperature $\left(T_{\mathrm{m}}\right)$ in the range from 110 to $142{ }^{\circ} \mathrm{C} .{ }^{[2]}$ Even as a part of block copolymers, the PFDMS crystallinity has already been addressed, ${ }^{[10,12,13,25]}$ but there is no systematic investigation available so far. 
The crystallization rate of polymers rises with the melting enthalpy for $100 \%$ crystalline material at otherwise equal conditions. It amounts to about $26 \mathrm{~J} \cdot \mathrm{g}^{-1}$ only for PFDMS $^{[26]}$ (compared to, e.g., $277 \mathrm{~J} \cdot \mathrm{g}^{-1}$ for $\mathrm{PE}^{[27]}$ and $197 \mathrm{~J} \cdot \mathrm{g}^{-1}$ for $\mathrm{PEO}^{[28]}$ ). PFDMS consequently crystallizes very slowly. Nevertheless, an attempt was made to determine its equilibrium melting temperature, $T_{\mathrm{m}, 0}$, which was found to be $T_{m, 0}=143{ }^{\circ} C^{[24]}$ using the linear Hoffmann-Weeks (HW) approach. ${ }^{[29]}$ The HW formalism is the commonly used procedure when $T_{\mathrm{m}, 0}$ of semicrystalline polymers has to be determined, especially because all data required are easily available from conventional differential scanning calorimetry (DSC) measurements: the samples are crystallized isothermally at different temperatures $T_{\mathrm{c}}$ and, subsequently, the melting temperatures, $T_{m}$, of the crystallites grown at the respective temperatures $T_{\mathrm{c}}$ are determined. Assuming a linear relationship between $T_{\mathrm{m}}$ and $T_{\mathrm{c}}, T_{\mathrm{m}, \mathrm{o}}$ is determined by linear extrapolation of the experimentally determined sets of $T_{\mathrm{m}}$ versus $T_{\mathrm{c}}$ pairs to $T_{\mathrm{m}}=T_{\mathrm{c}}$.

The HW procedure is indeed very convenient, but its general validity is still a matter of discussion; careful analysis of various semi-crystalline polymers showed a nonlinear $T_{\mathrm{m}}$ versus $T_{\mathrm{c}}$ behavior relatively frequently, especially when the studies were extended over a broader range of crystallization temperatures. ${ }^{[24,30]}$ One might speculate that there is in fact not even one semi-crystalline polymer showing a truly linear $T_{\mathrm{m}}$ versus $T_{\mathrm{c}}$ behavior. ${ }^{[31]}$ The main reason for nonlinearity in the $T_{\mathrm{m}}$ versus $T_{\mathrm{c}}$ relation is that the thickness $d_{c}$ of crystalline lamellae formed by a crystallizing polymer at a specific crystallization temperature $T_{\mathrm{c}}$ is not strictly inversely proportional to the extent of super-cooling, $\Delta T=T_{\mathrm{m}, 0}-T_{\mathrm{c}}$, applied during isothermal crystallization. ${ }^{[30,32]}$ This, however, is a necessary prerequisite for the HW analysis.

Facing the potentially intrinsic nonlinearity of the $T_{\mathrm{m}}$ versus $T_{\mathrm{C}}$ relation, a modified HW Equation was proposed for semi-crystalline polymers which explicitly takes into account the respective thicknesses of crystalline lamellae as an input parameter; this is the Gibbs-Thomson (GT) procedure, ${ }^{[33]}$ which was originally developed to analyze the size-dependent melting behavior of metallic nanoclusters. However, when taking the thickness of the crystalline lamellae, $d_{c}$, as the relevant size in the GT approach, it can be adapted to semi-crystalline polymers as well. Within this model the equilibrium melting temperature is obtained by plotting $T_{\mathrm{m}}$ versus $d_{\mathrm{c}}^{-1}$ for several samples crystallized isothermally at different crystallization temperatures $T_{\mathrm{c}}$. Linear regression following the Equation $T_{\mathrm{m}}=T_{\mathrm{m}, 0}-C d_{\mathrm{c}}^{-1}$, with $C$ being a constant, and extrapolation to $d_{c}^{-1}=0$, i.e., to infinite extension of the crystalline lamellae, results in the desired value of $T_{\mathrm{m}, 0}$. Obviously $d_{c}$ needs to be determined experimentally as additional information.
Validity of the GT approach has been confirmed for, e.g., PE and PP. ${ }^{[30,32]}$ Though scientifically more reliable, the GT procedure is not very common so far because $d_{c}$ has to be determined for several $T_{\mathrm{C}} \mathrm{S}$ using small-angle X-ray scattering (SAXS), or at least estimated by TEM, in addition to the DSC studies required anyway to measure the $T_{\mathrm{m}} \mathrm{s}^{[30]}$ Polymers might exist where indeed such efforts are not justified because sufficient linearity is ensured in their $T_{\mathrm{m}}$ versus $T_{\mathrm{C}}$ behavior. However, apparent inconsistencies in the case of PFDMS permit us to assume that this is not correct for this particular metallopolymer. For example, the published value $T_{m, 0}=143^{\circ} \mathrm{C}$ is neither in harmony with a melting temperature of $145^{\circ} \mathrm{C}$ observed for PFDMS crystallized under stretching conditions ${ }^{[26]}$ nor with the melting transition at $143^{\circ} \mathrm{C}$ found for PS- $b$-PFDMS (PS: polystyrene) diblock copolymers as will be shown later in this paper; by definition, $T_{\mathrm{m}, 0}$ corresponds to the $100 \%$ perfect crystallite of infinite size, which is experimentally inaccessible. ${ }^{[31,32]}$ As a consequence, the $T_{m, 0}$ reported so far might be in error to a more or less extent.

Since $T_{\mathrm{m}, 0}$ is indeed an important materials parameter, ${ }^{[31]}$ we decided to spend some effort in its careful re-determination for PFDMS homo- and block copolymers using both the HW and GT approaches. For this purpose, a low-molecular-weight and a high-molecular-weight PFDMS homopolymer sample and an almost symmetrical PS- $b$-PFDMS diblock copolymer were prepared. The latter showed a lamellar micro-morphology below its orderdisorder transition (ODT) temperature; based on preliminary SAXS studies carried out in the context of the present work, the PS- $b$-PFDMS diblock copolymer under investigation formed an isotropic monophasic melt above $T_{\mathrm{ODT}} \approx 207^{\circ} \mathrm{C}$ but microphase-separates at lower temperatures to give a lamellar micromorphology. This behavior is in agreement with the known fact that PS and PFDMS are partially miscible as long as the PFDMS is in its noncrystalline state. ${ }^{[34]}$ Upon PFDMS crystallization, however, the mixture changes from the weak-segregation into the strong-segregation regime. ${ }^{[35]}$

Due to very slow PFDMS crystallization, and in order to realize its crystallization at as high temperatures $T_{\mathrm{c}}$ as possible, the so-called self-seeding technique was applied for the preparation of isothermally crystallized samples. ${ }^{[32,36]}$ This technique is known to tremendously reduce the time required for nucleation, especially for slowly nucleating polymers at moderate super-coolings. For self-seeding crystallization, a pre-crystallized sample is initially needed which can be prepared by long-term isothermal annealing of the material. Later on, prior to the intended crystallization study, this pre-crystallized sample is heated very carefully, and for a very short period of time only, to a temperature $T_{\max }$ (i.e., the self-seeding temperature) that is just slightly above its melting temperature, $T_{\mathrm{m}}$. At this $T_{\max }$, the crystalline order vanishes to an extent 
that the material appears isotropically from the macroscopic point of view; crystalline regions cannot be detected, neither by calorimetry, nor by nuclear magnetic resonance, nor by microscopic techniques. ${ }^{[37-41]}$ It is still a matter of controversy whether some local chain

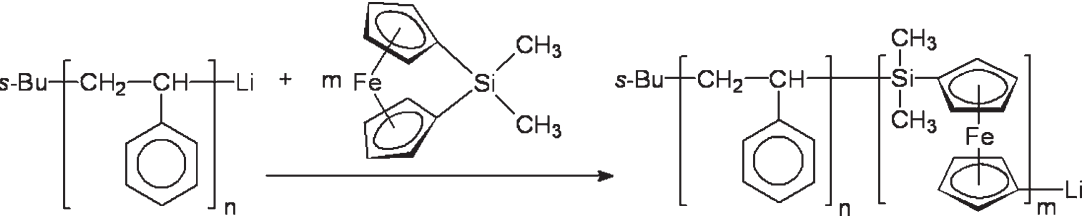

Scheme 1. Key step of the synthesis of the PS- $b$-PFDMS diblock copolymer. orientation or even tiny crystallites survive under the applied melting conditions. In any case, these remaining structural entities considerably support nucleation when the material is subsequently cooled down to the respective crystallization temperature. Crystallization supported by the self-seeding technique is the more powerful the smaller the $T_{\max }-T_{\mathrm{m}}$ interval and the shorter the annealing time at $T_{\max }$.

The consequences of self-seeding on the thickness of the crystalline lamellae and the $T_{\mathrm{m}}$ has hardly been addressed so far. ${ }^{[41]}$ It has been reported for PE and PP, ${ }^{[41]}$ however, that using this technique one ends up at the same crystal thickness as in the usual procedure of cooling a melt. Throughout, the experimentally determined melting temperatures, $T_{\mathrm{m}}$, and the thicknesses of the crystalline lamellae, $d_{c}$, were found to depend exclusively on the temperature $T_{\mathrm{c}}$ applied during isothermal crystallization. ${ }^{[42]}$ For PLLA, moreover, the data from the normal and self-seeding crystallizations fall on the same linear $T_{m}$ versus $1 / d_{c}$ curve. $^{[43]}$

Obviously, self-seeding does not influence the $T_{\mathrm{m}}$ versus $T_{\mathrm{c}}$ nor the $T_{\mathrm{m}}$ versus $1 / d_{\mathrm{c}}$ behavior. Nevertheless, we carried out additional studies to reconfirm that aspect explicitly for PFDMS. Using the correspondingly crystallized PFDMS samples, finally, the melting behavior was studied using DSC, and the thicknesses of the crystalline PFDMS lamellae were determined using synchrotron SAXS. The sets of data obtained in this manner were taken to calculate $T_{\mathrm{m}, \mathrm{o}}$ following the HW and the GT approaches, respectively, and thus to compare these two approaches with respect to their ability to yield the equilibrium melting temperature of PFDMS

\section{Experimental Part}

\section{Materials and Syntheses}

Dimethylsila[1]ferrocenophane (FS) was prepared as described recently ${ }^{[16,44]}$ and purified by repeated crystallization from hexane at $-60^{\circ} \mathrm{C}$ in the presence of trioctyl aluminum. Purification of styrene and the solvents was carried out as described elsewhere. ${ }^{[16]}$ sec-BuLi was prepared from sec-butyl chloride and lithium dispersion. PFDMS homopolymers having molar masses of $4.9 \mathrm{~kg} \cdot \mathrm{mol}^{-1}\left(P_{\mathrm{n}} \approx 20\right.$; "PFDMS-1") and $60.7 \mathrm{~kg} \cdot \mathrm{mol}^{-1}\left(P_{\mathrm{n}} \approx 250\right.$; "PFDMS-2"), were prepared following published procedures, i.e., by anionic polymerization of dimethylsila[1] ferrocenophane (FS). ${ }^{[16]}$ The polydispersity was PDI $=1.05$ and 1.03 , respectively. The PS-bPFDMS diblock copolymer was synthesized by sequential living

anionic polymerization in glass reactors equipped with break-seals for the addition of the reagents (Scheme 1 ). ${ }^{[8,11,22]}$ First, styrene was polymerized in cyclohexene at room temperature using the required amount of sec-BuLi. After completed conversion ( $\approx 12 \mathrm{~h})$, a solution of FS in cyclohexene was added by smashing the breakseal of the corresponding ampoule. The resulting mixture was stirred for $10 \mathrm{~min}$, thereby allowing the transformation of the styryllithium active centers to the ferrocenyllithium ones. Then, an equal volume of tetrahydrofurane (THF) was added in order to promote the FS propagation from the ferrocenyllithium-based macroanions. ${ }^{[8-11]}$ After stirring for a further $2 \mathrm{~h}$, the reaction was terminated with degassed methanol. The raw product was isolated by precipitation in hexane. Since it contained PS homopolymer impurities, it was purified by three-fold fractionation; the block copolymer was precipitated from its THF solution by dropwise addition of diethyl ether. The finally remaining traces of PS homopolymer $(\approx 5 \%)$ were accepted because it has the same molar mass as the PS block in the block copolymer and thus only swells the PS domains slightly. Also, it influences neither the PFDMS crystallization nor the sample's morphology. ${ }^{[9,45]}$ The resulting diblock copolymer has an overall molar mass $\left(\bar{M}_{\mathrm{n}}\right)$ of $24.3 \mathrm{~kg} \cdot \mathrm{mol}^{-1}$ (PDI = 1.05), with a PS block of $\bar{M}_{\mathrm{n}}=12.0 \mathrm{~kg} \cdot \mathrm{mol}^{-1}$ and a PFDMS block of $\bar{M}_{\mathrm{n}}=12.3 \mathrm{~kg} \cdot \mathrm{mol}^{-1}$. At room temperature, the volume fraction of PS in the amorphous and crystalline sample is 0.586 and 0.614 , respectively, taking a density of $1.05 \mathrm{~g} \cdot \mathrm{cm}^{-3}$ for the amorphous PS and densities of 1.294 and $1.455 \mathrm{~g} \cdot \mathrm{cm}^{-3}$ for the amorphous and crystalline PFDMS, respectively. ${ }^{[46]}$ The mass fraction of PFDMS in the sample is 0.494. This composition resulted in a lamellar micro-morphology at temperatures below ODT.

\section{Pre-Crystallization Procedure}

In order to prepare the pre-crystallized samples of homopolymers PFDMS-1 and PFDMS-2 needed for subsequent self-seeding crystallization studies, films were cast from methylene chloride solution. After evaporation of the solvent, the films were heated under vacuum ( $0.1 \mathrm{mbar}$ ) to $200^{\circ} \mathrm{C}$ for $60 \mathrm{~min}$ in order to melt all crystallites possibly formed during film preparation, and to remove traces of air and solvent trapped in the samples. Afterward, the samples were cooled down quickly $\left(20 \mathrm{~K} \cdot \mathrm{min}^{-1}\right)$ to $119^{\circ} \mathrm{C}$ for PFDMS- 1 and $125^{\circ} \mathrm{C}$ for PFDMS-2, which were found to be appropriate temperatures for pre-crystallization. At these temperatures, they were annealed for 60-70 $\mathrm{h}$.

In the case of the PS- $b$-PFDMS diblock copolymer, the powdery "as-synthesized" material was heated in aluminum containers under vacuum to $180^{\circ} \mathrm{C}$ for $60 \mathrm{~min}$. The molten material was pressed at around $145^{\circ} \mathrm{C}$ between two parallel steel plates to a film having a thickness of $0.3 \mathrm{~mm}$. The pressed film was put into a DSC pan, placed in a DSC instrument, heated to $180^{\circ} \mathrm{C}$ by $10 \mathrm{~K} \cdot \mathrm{min}^{-1}$, 
annealed for $10 \mathrm{~min}$ at this temperature, and finally quenched to $127^{\circ} \mathrm{C}$. At this temperature, the material was kept for $64 \mathrm{~h}$ for isothermal pre-crystallization.

\section{Self-Seeding Isothermal Crystallization}

For isothermal crystallization using the self-seeding technique, the pre-crystallized samples were heated to $T_{\max }$, i.e., just slightly above the highest observable PFDMS melting transition, at a rate of $10 \mathrm{~K} \cdot \mathrm{min}^{-1}$ in DSC (for PFDMS-1 and PFDMS-2), or $1 \mathrm{~K} \cdot \mathrm{min}^{-1}$ in situ at the beamline (for PS- $b$-PFDMS). $T_{\max }$ was typically $142^{\circ} \mathrm{C}$ for PFDMS- $1,145^{\circ} \mathrm{C}$ for PFDMS-2, and $147^{\circ} \mathrm{C}$ for the PS- $b$-PFDMS diblock copolymer, corresponding to a $\Delta T=T_{\max }-T_{\mathrm{m}}$ ranging between 1 and $3^{\circ} \mathrm{C}$. After annealing at $T_{\max }$ for $1-2 \mathrm{~min}$, the samples were cooled down by $30 \mathrm{~K} \cdot \mathrm{min}^{-1}$ to the respective isothermal crystallization temperature, $T_{\mathrm{c}}$. Depending on the respective rate of crystallization, the samples were annealed at $T_{\mathrm{c}}$ for 1-10 $\mathrm{h}$. Finally, $T_{\mathrm{m}}$ and $d_{\mathrm{c}}$ of the resulting crystalline materials were determined.

\section{Differential Scanning Calorimetry (DSC)}

Differential scanning calorimetry (DSC) measurements were carried out using a Perkin-Elmer DSC 7 instrument under an atmosphere of nitrogen. For determination of the $T_{\mathrm{m}}$ versus $T_{\mathrm{c}}$ behavior, the samples were scanned immediately after completed self-seeding crystallization at a heating rate of $10 \mathrm{~K} \cdot \mathrm{min}^{-1} \mathrm{up}$ to a temperature of $200^{\circ} \mathrm{C}$.

\section{Small Angle and Wide Angle Synchrotron X-Ray Scattering (SAXS and WAXS)}

SAXS and WAXS measurements were carried out at the beamline A2 in HASYLAB, DESY, Hamburg/Germany at a wavelength $\lambda=0.15 \mathrm{~nm}$. The samples were sandwiched between two layers of aluminum foil. The sample-to-detector distance for SAXS was around $2.9 \mathrm{~m}$. The accumulation time for each SAXS image and WAXS frame was $30 \mathrm{~s}$. Two-dimensional (2D) SAXS data and 1D WAXS data were recorded simultaneously. The SAXS patterns were calibrated by a rat tail tendon, and the WAXS patterns by poly(ethylene terephthalate). The 2D images were circularly integrated using the Fit2D program, ${ }^{[47]}$ normalized by the ionization intensity, and the background (i.e., air, aluminum) was subtracted.

For PS- $b$-PFDMS, the samples were crystallized and measured in situ at the beamline. For PFDMS homopolymers, the self-seeding crystallized samples were prepared in DSC prior to the X-ray measurements at DESY. The samples were measured at a heating rate of $1 \mathrm{~K} \cdot \mathrm{min}^{-1}$ from below to above $T_{\mathrm{c}}$, and the X-ray data were taken at $T_{\mathrm{X} \text {-ray }}=T_{\mathrm{c}}$. Because there was a delay of 4-9d between sample preparation and the X-ray measurements, it was necessary to ensure that the material's structure did not change during that storage at room temperature. In order to verify this, fractions of these stored samples were scanned in a DSC, and the DSC curves thus determined were compared with those obtained from DSC runs carried out with "fresh" samples, i.e., immediately after crystallization at $T=T_{\mathrm{c}}$. The DSC measurements reliably showed exactly the same traces, indicating that the crystalline morphology did not change during storage at room temperature.

From the SAXS data, the thicknesses of the crystallite lamellae, $d_{c}$, were calculated for the PFDMS homopolymers following the correlation analysis developed by Strobl. ${ }^{[31]}$ In this type of analysis, the structure correlation function $K(z)$ is calculated by cos-Fouriertransformation from the isotropic SAXS pattern $I(q)$,

$K(z)=C \int_{0}^{\infty} \cos (q z) q^{2} I(q) \mathrm{d} q$,

where $C$ is a constant which reflects the scattering power of the material. If the structure is a regular stack of amorphous and crystalline layers, analysis of the course of that function then yields the values of long period $d$ and lamellar thickness $d_{c}$.

\section{Results and Discussion}

\section{Conventional versus Self-Seeding Poly(ferrocenyl dimethylsilane) (PFDMS) Crystallization}

Poly(ferrocenyl dimethylsilane) (PFDMS) homopolymers crystallize very slowly due to their very low melting enthalpy. Consequently, both samples PFDMS-1 and PFDMS-2 did not crystallize when cooling the melts from $200{ }^{\circ} \mathrm{C}$ to room temperature at rates higher than around $30 \mathrm{~K} \cdot \mathrm{min}^{-1}$. If the cooling rate was only $1 \mathrm{~K} \cdot \mathrm{min}^{-1}$, however, they crystallized nicely. Isothermal PFDMS crystallization also proved to be feasible, provided that an appropriate crystallization temperature $80^{\circ} \mathrm{C}<T_{\mathrm{C}}<$ $130^{\circ} \mathrm{C}$ was selected.

Poly(ferrocenyl dimethylsilane) (PFDMS) crystallization in the PS- $b$-PFDMS diblock copolymer, on the other hand, was found to be even much slower than in the homopolymers; DSC and WAXS studies showed that the PFDMS blocks did not crystallize even if the melt was cooled down from $180^{\circ} \mathrm{C}$ at only $0.5 \mathrm{~K} \cdot \mathrm{min}^{-1}$. Vitrification of the PS layers at super-coolings required for efficient PFDMS nucleation and crystal growth might be the reason for the suppressed crystallization observed in the block copolymer. Partial miscibility of PS and amorphous PFDMS at elevated temperatures might additionally hinder proper PFDMS nucleation. ${ }^{[48]}$ Nevertheless, PFDMS crystallization in the PFDMS- $b$-PS diblock copolymer was proven to be possible if annealing was done at $127^{\circ} \mathrm{C}$ for $64 \mathrm{~h}$ : two sharp peaks appear in the WAXS patterns at $q=1.44$ and $1.64 \mathrm{~nm}^{-1}$. They roughly correspond to the 200 and 010 reflections at 1.50 and $1.66 \mathrm{~nm}^{-1}$, respectively, of the meltcrystallized PFDMS homopolymer. ${ }^{[24,26]}$ Thus, the crystalline morphology of PFDMS in the diblock copolymer is obviously almost the same as in those homopolymers.

Prior to the intended investigation of the equilibrium melting temperature of PFDMS, it was confirmed by suitable experiments that no undesired changes of PFDMS 

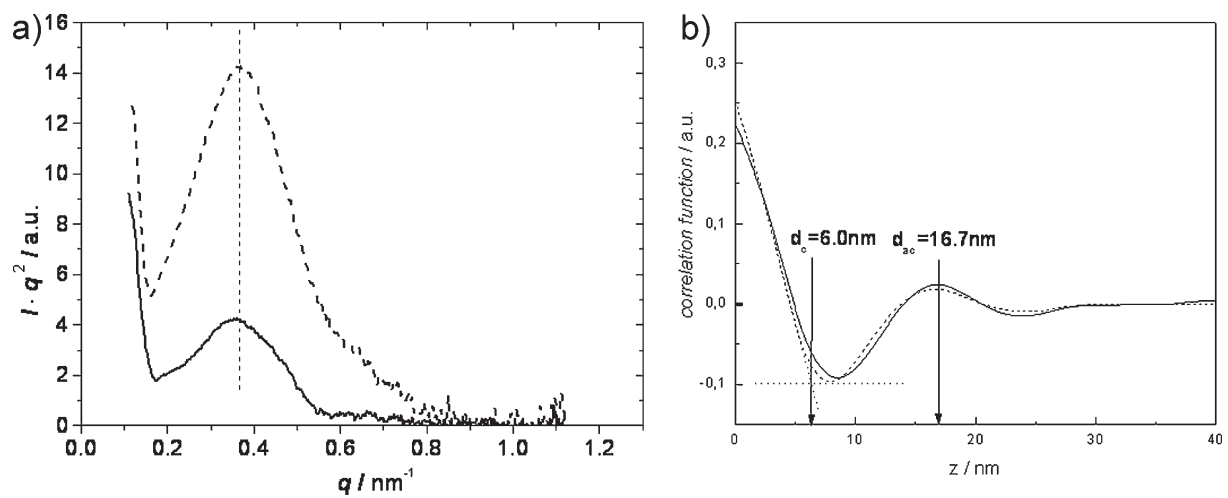

Figure 1. SAXS of two samples of PFDMS-2 isothermally crystallized at $T_{\mathrm{c}}=120^{\circ} \mathrm{C}$ (solid line) from the "regular" isotropic melt at $180{ }^{\circ} \mathrm{C}$ (i.e., without self-seeding), and (dashed line) using the self-seeding procedure as specified in the text; (a) scattering pattern, (b) corresponding correlation function. The solid curve in (a) was magnified 3.4 times for ease of comparison.

crystallization and morphology are induced by application of the self-seeding procedure. To this end, pairs of samples were crystallized at different $T_{\mathrm{c}} \mathrm{s}$, once with and once without self-seeding, and then compared using DSC, WAXS, and SAXS. Figure 1 shows two representative SAXS curves obtained from PFDMS-2 after isothermal crystallization at $T_{\mathrm{C}}=120^{\circ} \mathrm{C}$ with and without self-seeding.

Throughout, the SAXS studies proved that identical values of $q_{\max }$ are found for samples crystallized at the same $T_{\mathrm{C}}$ with and without self-seeding (Figure 1a). The correlation function analysis ${ }^{[49]}$ derived from the SAXS curves indicates that the thicknesses of the crystalline PFDMS lamellae are the same for both samples (Figure $1 \mathrm{~b}$ ). Thus, self-seeding does not alter the thicknesses of the crystalline lamellae ${ }^{a}$.

Next it was proved that the extension of self-seeding nuclei has no influence on the samples' melting temperatures. For this sake, a series of materials pre-crystallized under identical conditions was heated to different temperatures $T_{\max }$, and annealed there for different periods of time, prior to cooling down to the respective crystallization temperature $T_{\mathrm{c}}$. After finalized self-seeding crystallization, the materials were scanned in DSC runs to see whether changes can be found in the melting temperature $T_{\mathrm{m}}$. Figure 2 shows two representative DSC heating runs for two samples of the PS- $b$-PFDMS diblock copolymer which were prepared at different self-seeding conditions. The melting enthalpies were found to be 8.9 and $6.8 \mathrm{~J} \cdot \mathrm{g}^{-1}$ for the materials annealed at 145 and $147^{\circ} \mathrm{C}$, respectively. The melting temperatures, however, did not differ and hence it is evident that the strength of the self-seeding nuclei does

\footnotetext{
a The long period $d_{\mathrm{ac}}$ is determined as the location of the first maximum of the correlation function $K(z)$ and a sub-thickness $d$ as the value of $z$ where the tangent at the first minimum of $K(z)$ intersects with the straight line through the first turning point of $K(z)$. Whether $d$ represents the lamellar thickness $d_{c}$ or $d_{\mathrm{a}}$ can be decided by means of the material's crystallinity as determined by e.g. DSC
}

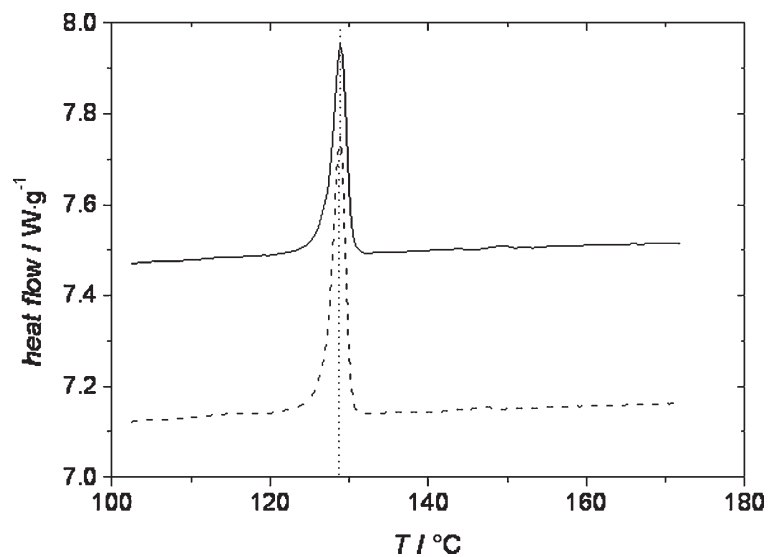

Figure 2. Differential scanning calorimetry (DSC) heating runs at $10 \mathrm{~K} \cdot \mathrm{min}^{-1}$ for PS- $b$-PFDMS diblock copolymer samples pre-crystallized at $127^{\circ} \mathrm{C}$ for $64 \mathrm{~h}$, heated to the self-seeding temperatures $T_{\max }=147^{\circ} \mathrm{C}$ (solid line) or $T_{\max }=145^{\circ} \mathrm{C}$ (dashed line) prior to quenching at $20 \mathrm{~K} \cdot \mathrm{min}^{-1}$ to the isothermal crystallization temperature $T_{\mathrm{c}}=100^{\circ} \mathrm{C}$. At $T_{\mathrm{c}}$, both samples were allowed to crystallize for $180 \mathrm{~min}$.

not induce differences in the materials' behavior. It is only the degree of crystallinity which can differ to some extent depending on the strength of the self-seeding nuclei.

The third aspect to be analyzed was whether the crystalline morphology is affected by the self-seeding procedure and/or the isothermal crystallization temperatures $T_{\mathrm{c}}$. WAXS studies were carried out, therefore, on samples crystallized at different $T_{\mathrm{C}} \mathrm{S}$, with and without selfseeding. Figure 3 shows three characteristic WAXS patterns obtained for the high-molecular-weight PFDMS-2 crystallized at $T_{\mathrm{C}}=100,120$, and $135^{\circ} \mathrm{C}$ using an identical selfseeding procedure. The WAXS patterns essentially coincide, allowing the conclusion that no change in the crystalline morphology is detectable in the studied range of temperatures. Thus, we can be sure now that isothermal crystallization at different $T_{\mathrm{C}}$ s with and without self-seeding leads 


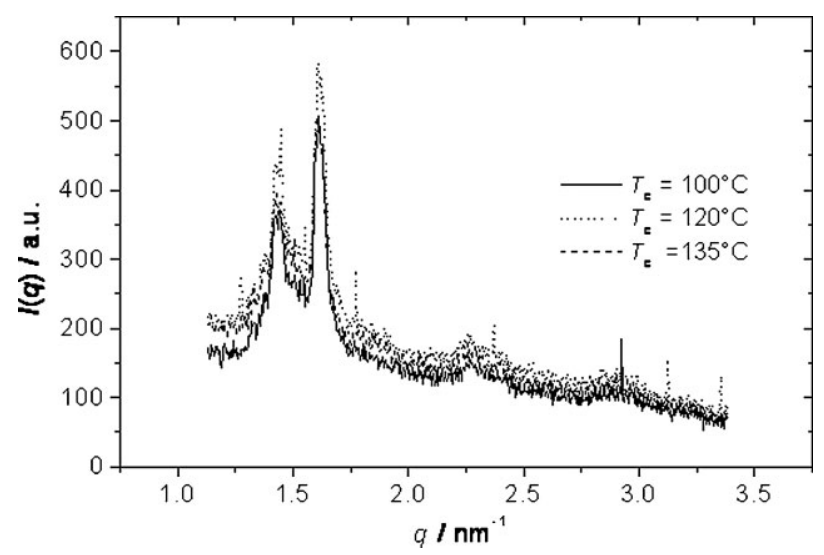

Figure 3. WAXS patterns for PFDMS-2 recorded at different $T_{\mathrm{c}}$ after self-seeding crystallization.

to the same crystal morphology. All in all, the studies proved that application of the self-seeding technique is legitimate in the subsequent investigations planned to determine the $T_{\mathrm{m}, 0}$ of PFDMS.

\section{Crystal Growth Rate}

Isothermal crystallization of the self-seeded PFDMS samples causes an exothermal peak in the DSC thermograms as shown in Figure 4 for PFDMS-2. Such graphs allow complete quantification of crystallization kinetics by integrating the peak areas as a function of crystallization time. For the sake of simplicity, we characterize this crystallization curve by the time $t_{\mathrm{p}}$ of highest crystallization rate, i.e., the time where the exothermal peak maximum appears. These times were plotted in Figure 5 as a function of $T_{\mathrm{C}}$ for

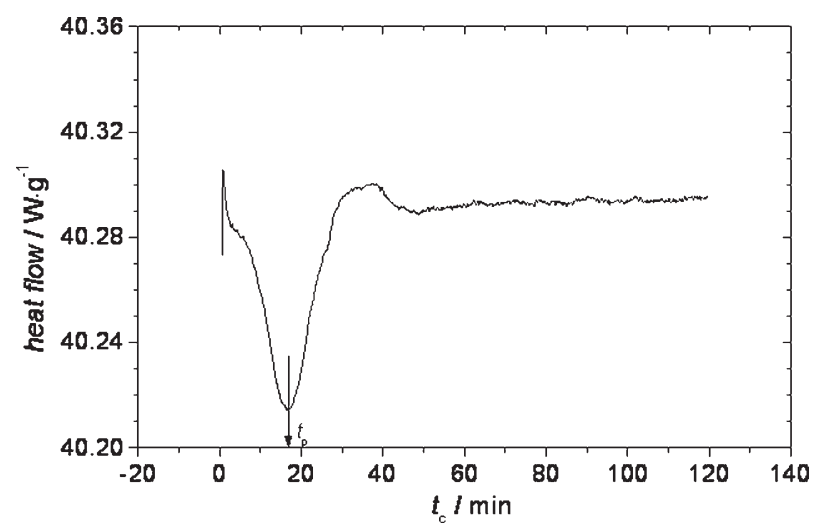

Figure 4. Representative isothermal heat flow as function of crystallization time $t_{c}$ as measured by DSC for the isothermal self-seeding crystallization of PFDMS-2 at $T_{\mathrm{c}}=90^{\circ} \mathrm{C}$. The peak time, $t_{\mathrm{p}}$, used in the following evaluation is indicated.

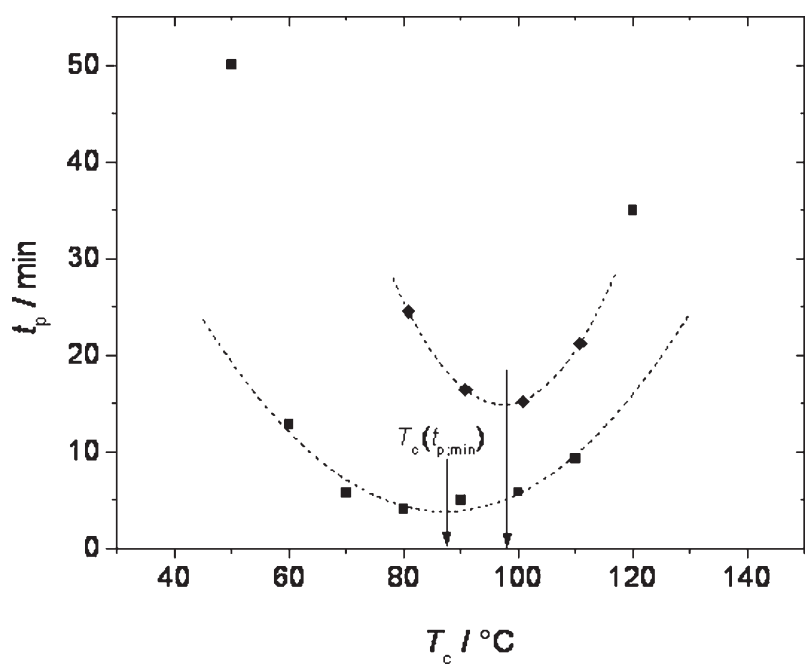

Figure 5. Rate of self-seeding isothermal crystallization as expressed by $t_{\mathrm{p}}$ of the PFDMS homopolymers at different crystallization temperatures, $T_{c}$, for PFDMS-1 ( $\square \square$ ) and PFDMS-2 $(\diamond \diamond \diamond)$. The lines through the data points are just a visual guide. The arrows indicate the $T_{\mathrm{c}}$ where $t_{\mathrm{p}}$ has its minimum.

homopolymers PFDMS- 1 and PFDMS- 2 in the experimentally accessible range $60^{\circ} \mathrm{C} \leq T_{\mathrm{c}} \leq 120^{\circ} \mathrm{C}$.

The maximum rates of isothermal crystallization were determined to be at $T_{\mathrm{c}, \max } \approx 87^{\circ} \mathrm{C}$ for PFDMS- 1 and at $T_{\mathrm{c}, \max } \approx 97^{\circ} \mathrm{C}$ for PFDMS-2. A higher temperature $T_{\mathrm{c}, \max }$ for the higher molecular weight sample is reasonable due to lower chain mobility. For $T_{\mathrm{c}} \leq 60^{\circ} \mathrm{C}$ and $T_{\mathrm{c}}>120^{\circ} \mathrm{C}$, it was not possible to determine reliable values of $t_{\mathrm{p}}$ because of the tremendous broadening and insufficient resolution of the exothermal peaks. For $T_{\mathrm{c}} \leq 60^{\circ} \mathrm{C}$, frozen chain dynamics might play a role whereas at $T_{\mathrm{C}}>120^{\circ} \mathrm{C}$ the low undercooling - and thus the very slow crystal growth - might be relevant.

We note that for the PS- $b$-PFDMS diblock copolymer an analogous estimation of the temperature dependency of the crystallization kinetics was not possible using DSC since self-seeded samples were prepared only for X-ray scattering. Then, the crystal growth rate is very slow, and the samples remained nearly amorphous even under apparently appropriate crystallization conditions, i.e., after the self-seeding approach and for very long crystallization times. For example, the material almost did not crystallize after annealing at $T_{\mathrm{C}}=110^{\circ} \mathrm{C}$ for about $4.5 \mathrm{~h}$.

\section{Degree of Crystallinity}

As stated above, the crystalline morphology of the PFDMS is the same for all $T_{\mathrm{C}} \mathrm{S}$ in the homopolymers and the diblock copolymer. Therefore, we apply for the moment the published melting enthalpy of $\Delta H_{0, \text { PFDMS }}=26 \mathrm{~J} \cdot \mathrm{g}^{-1}$ for 
Table 1. Normalized melting enthalpies for PFDMS-1, PFDMS-2, and the PS- $b$-PFDMS.

\begin{tabular}{|c|c|c|c|c|}
\hline \multirow[t]{2}{*}{ Samples } & DSC heating rate & Melting enthalpy & Crystallinity & Crystallinity \\
\hline & ${ }^{\circ} \mathrm{C} \cdot \min ^{-1}$ & $\mathrm{~J} \cdot \mathrm{g}^{-1}$ & $\%^{\mathrm{a})}$ & $\%^{b)}$ \\
\hline PFDMS-1 & 2 & 19.3 & 72 & 49 \\
\hline PFDMS-2 & 2 & 14.7 & 54 & 37 \\
\hline PS- $b$-PFDMS & 2 & $26.7^{c)}$ & 99 & 68 \\
\hline PFDMS-1 & 10 & 19.7 & 73 & 50 \\
\hline PFDMS-2 & 10 & 12.7 & 47 & 32 \\
\hline PS- $b$-PFDMS & 10 & $23.5^{\mathrm{c})}$ & 87 & 60 \\
\hline
\end{tabular}

${ }^{\text {a) }} \Delta H_{0}=26 \mathrm{~J} \cdot \mathrm{g}^{-1}{ }^{[26]} ;{ }^{\mathrm{b})} \Delta H_{0}=38 \mathrm{~J} \cdot \mathrm{g}^{-1}$ (cf. text); ${ }^{\mathrm{c}}$ Normalized with respect to the mass fraction of PFDMS.

$100 \%$ crystallized PFDMS ${ }^{[26]}$ to estimate the degrees of crystallinity for both sets of materials. The highest determined DSC melting enthalpies were $19.9 \mathrm{~J} \cdot \mathrm{g}^{-1}$ for the low-molecular-weight PFDMS-1 (after annealing at $119^{\circ} \mathrm{C}$ for $66 \mathrm{~h}$ ), and $14.6 \mathrm{~J} \cdot \mathrm{g}^{-1}$ for the high-molecularweight homopolymer PFDMS-2 (annealing at $125^{\circ} \mathrm{C}$ for $67 \mathrm{~h})$. Obviously, the degrees of crystallinity in the PFDMS homopolymers do not exceed 50-75\% (Table 1 and Figure 6). In the PS- $b$-PFDMS block copolymer, on the other hand, the enthalpies determined from the normalized melting peak areas were considerably larger. Values of $23-26 \mathrm{~J} \cdot \mathrm{g}^{-1}$ were observed upon crystallization at $127^{\circ} \mathrm{C}$ for $64 \mathrm{~h}$, which would correspond to PFDMS crystallinities of $90-100 \%$. This is rather unlikely, however. It is not an easy task to identify the completion of isothermal crystallization. With prolongation of the crystallization time, the melting enthalpy may increase slightly further. The data of Table 1 may consequently be too low, and the DSC degrees

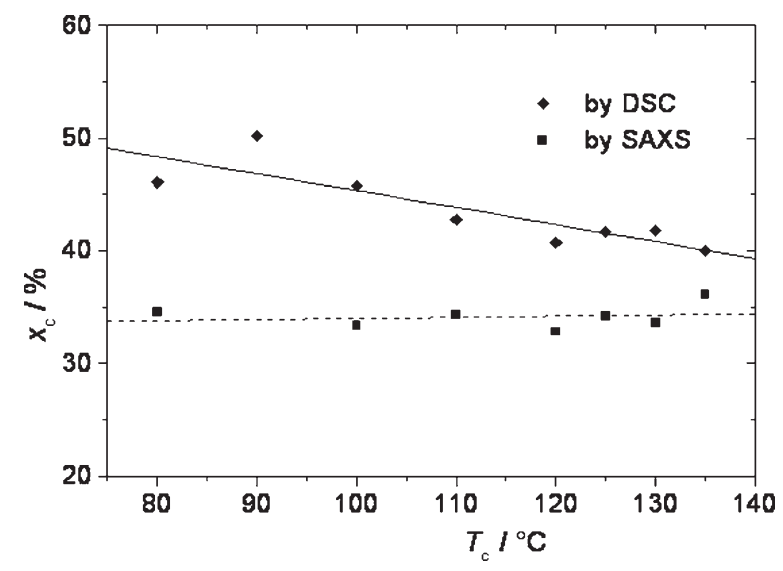

Figure 6. Degrees of crystallinity $x_{\mathrm{c}}$ by DSC $(\bullet \bullet)$ and SAXS (घ口) of PFDMS-2 samples crystallized at different $T_{\mathrm{c}} \mathrm{S}$. of crystallinity may even be higher than those given in Figure 6.

One might argue that the published $\Delta H_{0, \text { PFDMS }}=26 \mathrm{~J} \cdot \mathrm{g}^{-1}$ is too low. Therefore, for comparison purposes, the degrees of crystallinity of the same samples were additionally determined by 1D analysis of the SAXS data recorded at different $T_{\mathrm{C}} \mathrm{S}$, following the correlation analysis. Figure 6 shows the calculated degrees of crystallinity for PFDMS-2. It is evident that the crystallinities obtained from SAXS are clearly below those from DSC data. Usually, the inverse situation is found; especially for samples with low crystallinity, the degrees of crystallinity determined from DSC are lower than those determined from SAXS measurements. Hence, the larger values of crystallinity from the DSC data in the case of our studies might indicate that the true value of $\Delta H_{0, \text { PFDMS }}$ is actually higher than $26 \mathrm{~J} \cdot \mathrm{g}^{-1}$. Assuming identical DSC and SAXS crystallinities, $\Delta H_{0, \text { PFDMS }}=(38 \pm 3) \mathrm{J} \cdot \mathrm{g}^{-1}$ would result. The DSC crystallinities based on that value are given in the last column of Table 1.

Using that $\Delta H_{0}$, however, the block copolymer crystallinity still remains above that of the homopolymer. Possibly, $\Delta H_{0}=38 \mathrm{~J} \cdot \mathrm{g}^{-1}$ is not valid for the block copolymer either. Although the crystalline morphology of the PFDMS is almost the same in the homopolymer and in the block copolymer, the ideal melting enthalpies must not necessarily be the same; the amorphous phases of the homopolymer and the block copolymer melts may have different enthalpic levels. If it is speculated that the crystallinity of the block copolymer must be below that of the homopolymer, then $\Delta H_{0}$ (block) must be greater than $\Delta H_{0}$ (homo). This, however, seems rather unlikely. We therefore rely on the result that the crystallinity of the block copolymer is higher than that of the homopolymer. The problem is treated in more detail, and a reliable explanation of the crystallization kinetics and the structural background will be presented in a forthcoming paper. 


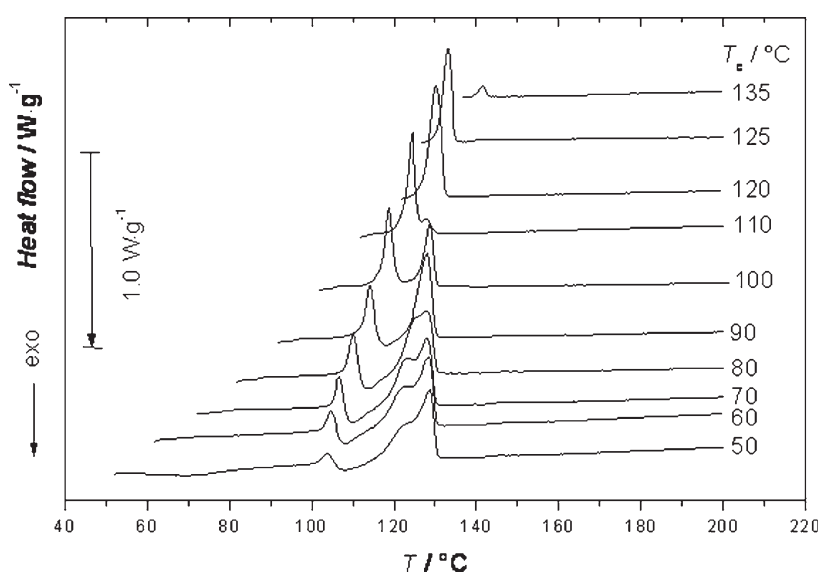

Figure 7. Heat flow versus temperature curves for PFDMS-1, scanned immediately after self-seeding crystallization at different isothermal temperatures. Heating rate: $10 \mathrm{~K} \cdot \mathrm{min}^{-1}$.

\section{The $T_{\mathrm{m}}$ versus $T_{\mathrm{c}}$ Behavior}

The DSC heating runs for the homopolymers PFDMS-1 and PFDMS-2 after isothermal self-seeding crystallization at different $T_{C} S$ are shown in Figure 7 and 8 , respectively. Multiple melting peaks were found for both homopolymers when crystallized at lower $T_{\mathrm{c}}$, whilst for higher $T_{\mathrm{c}}$ only a single melting endotherm can be identified. The lower the $T_{\mathrm{c}}$, the lower the temperature at which the first endotherm appears. For the low-molecular weight sample PFDMS-1, moreover, an exothermal transition can be seen if isothermal crystallization was performed at $T_{\mathrm{C}} \leq 90^{\circ} \mathrm{C}$ (Figure 7). This exothermic peak is attributed to recrystallization during the heating run. ${ }^{[32]}$ Re-crystallization occurs when rather unstable original crystallites as formed during isothermal annealing at lower $T_{\mathrm{C}} \mathrm{s}$ melt very early during the heating run, and can thus re-crystallize instantaneously again to give more stable crystallites. Later, these new crystallites melt again but only at clearly higher temperatures. In the case of the high-molecularweight PFDMS-2 (Figure 8), an exothermic re-crystallization peak is not detectable, maybe due to the lower overall chain mobility. This indicates that, as the molecular weight increases, the tendency of the PFDMS chains to re-crystallize during the heating scans decreases. On the other hand, absence of an exothermic peak during heating runs does not necessarily indicate absence of re-crystallization. ${ }^{[50]}$ Furthermore, occurrence of re-crystallization depends on the heating rate; during WAXS measurements where a heating rate of $1 \mathrm{~K} \cdot \mathrm{min}^{-1}$ was applied, re-crystallization has also been observed for the PFDMS-2 samples at all applied $T_{\mathrm{c}}$.

For the PS- $b$-PFDMS diblock copolymer, the corresponding DSC curves measured immediately after completed self-seeding crystallization are given in Figure 9. Here, a single melting endotherm can be observed for all samples, independent of the applied $T_{\mathrm{c}}$. In addition, there is no indication of an exotherm pointing toward re-crystallization during the DSC run. For further evaluation of the DSC traces, the position of the first melting peak is taken as the relevant value of $T_{m}$, because it can be reliably assumed that this peak is related to the crystallites formed during isothermal crystallization.

Since the presence of melting peaks at different temperatures as found for homopolymers at lower $T_{\mathrm{c}}$ is related to crystalline lamellae of different thicknesses, the DSC results indicate that the thicknesses of the crystalline lamellae in the diblock copolymer are defined much better than those in the homopolymers. This is a well-known phenomenon. ${ }^{[51]}$ This observation might be summarized by the statement that the more perfect the lamellar structure in a sample, the lower its tendency to recrystallize.

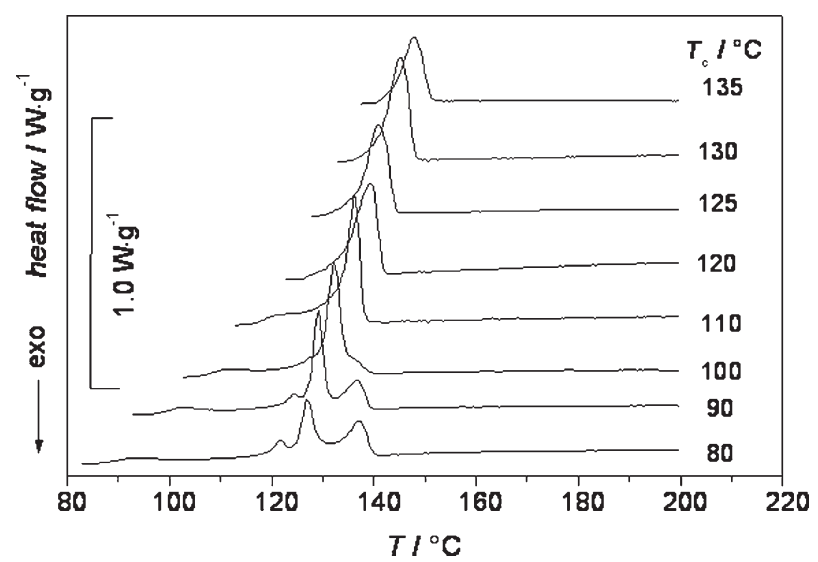

Figure 8. Heat flow versus temperature curves for PFDMS-2 scanned immediately after the self-seeding crystallization at different temperatures. Heating rate: $10 \mathrm{~K} \cdot \mathrm{min}^{-1}$.

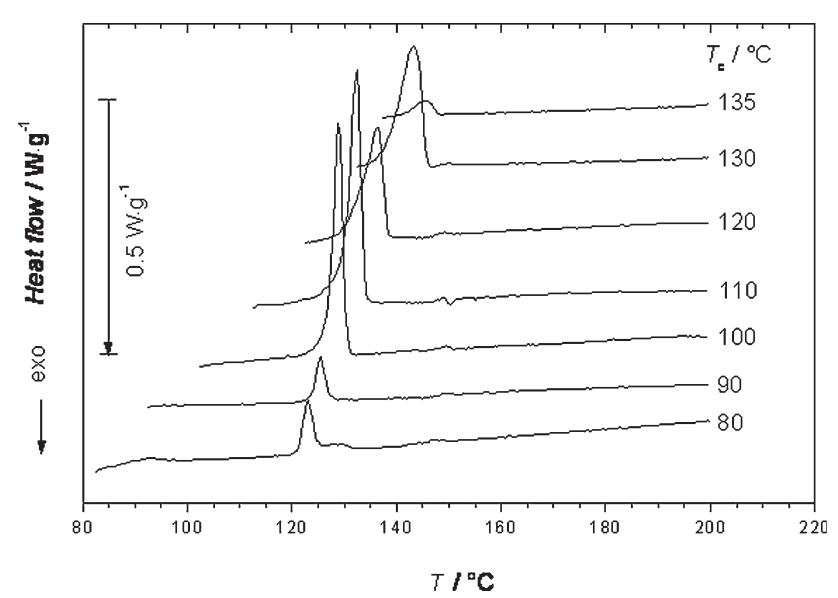

Figure 9. Heat flow versus temperature curves for the PS- $b$ PFDMS diblock copolymer after self-seeding crystallization at different temperatures. Heating rate: $10 \mathrm{~K} \cdot \mathrm{min}^{-1}$. 


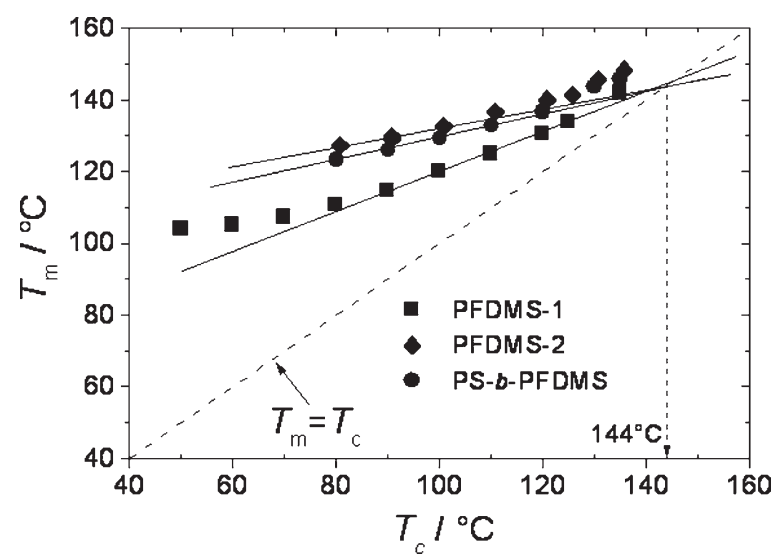

Figure 10. Determination of $T_{\mathrm{m}, \mathrm{o}}$ following the HW formalism: $T_{\mathrm{m}}$ versus $T_{\mathrm{c}}$ plots for PFDMS-1 ( $\square \square$ ), PFDMS-2 $(\diamond \bullet$ ), and PS- $b$

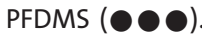

\section{The Equilibrium Melting Temperature $T_{\mathrm{m}, \mathrm{o}}$}

\section{The Hoffmann-Weeks (HW) Procedure}

As discussed above, the peak positions of the first melting endotherm observed has been taken as the melting temperature $T_{\mathrm{m}}$ of PFDMS homo and diblock copolymers crystallized at different temperatures $T_{\mathrm{c}}$. For the $T_{\mathrm{m}, 0}$ determination following the HW procedure, $T_{\mathrm{m}}$ is plotted as a function of $T_{\mathrm{c}}$ (Figure 10). Obviously, a nonlinear $T_{\mathrm{m}}$ versus $T_{\mathrm{c}}$ relationship is found for all samples. If the data are nevertheless extrapolated linearly, taking into account only the data measured in the $80^{\circ} \mathrm{C} \leq T_{\mathrm{c}} \leq 120^{\circ} \mathrm{C}$ range, a value of $T_{\mathrm{m}, 0}=144^{\circ} \mathrm{C}$ is found, which is in excellent agreement with the one reported in the literature. ${ }^{[24]}$

It is surprising, however, that the values of $T_{\mathrm{m}, 0}$ of the homopolymers and the block copolymer coincide. Moreover, we cannot ignore that the $T_{\mathrm{m}}$ versus $T_{\mathrm{c}}$ data deviate substantially from a linear behavior especially for those samples obtained by isothermal crystallization at rather high values of $T_{\mathrm{c}}$. Also, for PFDMS-2, deviation from a linear behavior is found even if $T_{\mathrm{C}}$ is lower than $80^{\circ} \mathrm{C}$. This nonlinearity may be due to the fact that the thicknesses of the crystallite lamellae are not strictly inversely proportional to the super-cooling $\Delta T$, i.e., $T_{\mathrm{m}, 0}-T_{\mathrm{c}}$.

\section{The Gibbs-Thomson (GT) Procedure}

Since the HW analysis fails due to the obvious nonlinearity of the $T_{\mathrm{m}}$ versus $T_{\mathrm{c}}$ relation, a more reliable value of $T_{\mathrm{m}, 0}$ of PFDMS was determined using the GT equation, where the lamellae thickness is explicitly taken into account. The required values of the crystallites' lamellae thicknesses, $d_{c}$ were obtained from SAXS patterns. Figure 11 shows some representative scattering curves for PFDMS-2. From these scattering data, the thicknesses of the crystallite lamellae, $d_{c}$, were calculated for the PFDMS homopolymers following

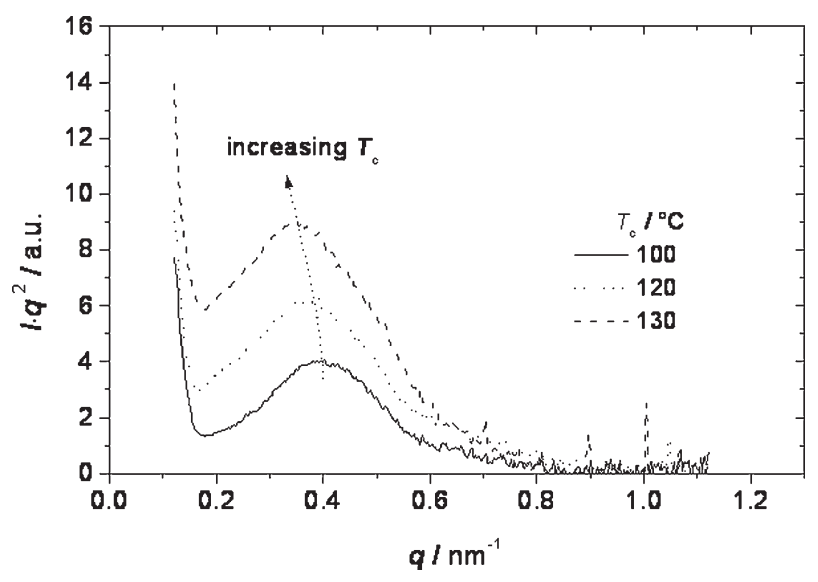

Figure 11. Representative synchrotron SAXS curves obtained for PFDMS-2 samples.

the correlation analysis. For the PS- $b$-PFDMS diblock copolymer, it must considered that the diblock copolymer by itself forms a lamellar micro-morphology, consisting of a stack of its amorphous (PS) and crystallizable (PFDMS) part. If the PFDMS chains are oriented perpendicular to the lamellae's surfaces, each semi-crystalline PFDMS layer consists of two layers of PFDMS crystallites (Figure 12), and the correlation analysis yields $2 d_{\mathrm{c}}$.

The $T_{\mathrm{m}}$ versus $d_{\mathrm{c}}^{-1}$ pairs thus obtained are plotted in Figure 13 for the PFDMS-2 and the diblock copolymer, taking the $T_{\mathrm{m}} \mathrm{s}$ from the DSC scans (Figures 8 and 9) and the $d_{\mathrm{c}}$ values from SAXS. The linear fit yields $T_{\mathrm{m}, 0}=(215 \pm 11)^{\circ} \mathrm{C}$ for PFDMS- 2 and $T_{\mathrm{m}, 0}=(179 \pm 5){ }^{\circ} \mathrm{C}$ for PS- $b$-PFDMS. Different values of $T_{\mathrm{m}, 0}$ for PFDMS as homopolymer and being part of a block copolymer are reasonable because of the different environments for the PFDMS crystallites. In any case, our findings prove that the $T_{\mathrm{m}, 0}$ of PFDMS given in the literature $^{[24]}$ is far too low.

\section{Discussion and Conclusion}

Failure of the HW approach, or discrepancies between the results of HW and GT analyses, have already been reported
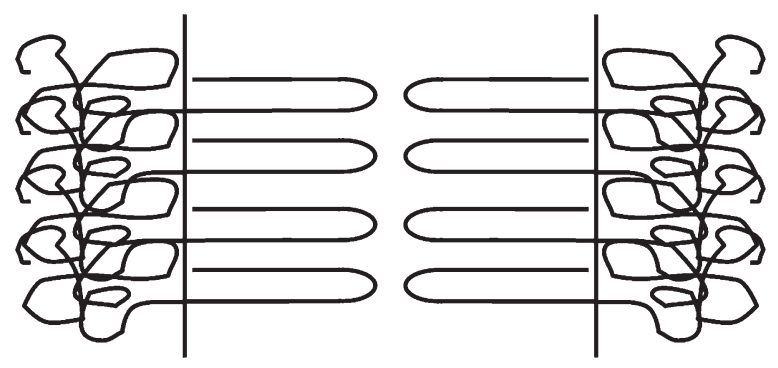

Figure 12. Schematic drawing of assumed structure and orientation of the PFDMS crystallites in the microphase-separated lamellar PS- $b$-PFDMS diblock copolymer. 


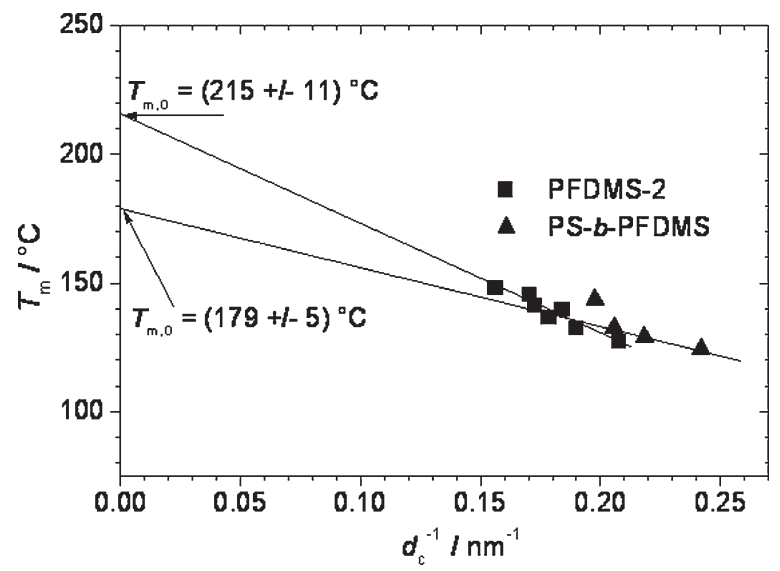

Figure $13 . T_{\mathrm{m}}$ versus $d_{\mathrm{c}}^{-1}$ for PFDMS-2 and for PS- $b$-PFDMS diblock copolymer.

several times. ${ }^{[52]}$ The HW approach for the determination of the equilibrium melting temperature $T_{\mathrm{m}, \mathrm{o}}$ presupposes that $T_{\mathrm{m}}$ and $T_{\mathrm{C}}$ differ due to lamellar thickening upon heating but are both proportional to the reverse $d^{-1}$ of the respective lamellar thicknesses. In contrast, the GT approach demands only that $T_{\mathrm{m}, 0}-T_{\mathrm{m}}=c_{1}+c_{2} / d_{\mathrm{c}}^{-1}$ (where $c_{1}$ and $c_{2}$ represent otherwise constant thermodynamic parameters). Obviously, the HW presuppositions are sharper and, consequently, more often violated than the GT one. The violation of the HW presuppositions causes a nonlinear dependency of $T_{\mathrm{m}}$ on $T_{\mathrm{C}}{ }^{[53]}$ as found particularly here for PFDMS as a homopolymer and as a component of a block copolymer. The HW analysis of the dependency of $T_{\mathrm{m}}$ on $T_{\mathrm{c}}$ - neglecting the mentioned nonlinearity - confirmed a value of $T_{\mathrm{m}, 0}=144^{\circ} \mathrm{C}$ as reported in the literature $\mathrm{e}^{[24]}$ and also determined by HW analysis. The GT approach, in contrast, yielded $T_{\mathrm{m}, 0}=215^{\circ} \mathrm{C}$ for the homopolymer and $T_{\mathrm{m}, 0}=179^{\circ} \mathrm{C}$ for the block copolymer component. For the reasons given above we are convinced that these values are more reliable than the former ones. Moreover, their difference reasonably reflects the different thermodynamic boundary conditions for crystallization in the homopolymer and in the block copolymer.

Another remarkable result of our investigations is that PFDMS as a component of a block copolymer crystallizes to a higher extent than as a homopolymer. This result of DSC experiments holds although comparison with SAXS analyses indicates that the heat of fusion of PFDMS $\Delta H_{0}=26 \mathrm{~J} \cdot \mathrm{g}^{-1}$ reported in the literature ${ }^{[26]}$ may be too low.

Acknowledgements: The authors would like to thank the Deutsche Forschungsgemeinschaft (DFG), the Fonds der Chemischen Industrie (FCI), and the Dr. Otto Röhm foundation for financial support of this work. The helpful discussions with Prof. G. Strobl (Freiburg University), and the technical support provided by Dr. S. S. Funari (DESY, Hamburg), and Mrs. Y. Xu (DKI) for the $\mathrm{X}$-ray measurements, are gratefully acknowledged.

Received: December 22, 2009; Revised: February 27, 2010; DOI: $10.1002 /$ macp. 200900718

Keywords: block copolymers; Gibbs-Thomson equation; Hoffmann-Weeks equation; melting point; polyferrocenylsilane

[1] D. A. Foucher, B.-Z. Tang, I. J. Manners, J. Am. Chem. Soc. 1992, $114,6246$.

[2] I. Manners, Synthetic Metal-Containing Polymers, VCH, Weinheim 2004

[3] A. S. Abd-El-Aziz, Macromol. Rapid Commun. 2002, 23, 995.

[4] K. Kulbaba, I. Manners, Macromol. Rapid Commun. 2001, 22, 711.

[5] I. Korczagin, R. G. H. Lammertink, M. A. Hempenius, S. Golze, G. J. Vancso, Adv. Polym. Sci. 2006, 200. 91.

[6] D. E. Herbert, U. F. J. Mayer, I. Manners, Angew. Chem., Int. Ed. 2007, 46, 5060

[7] V. Bellas, M. Rehahn, Angew. Chem., Int. Ed. 2007, 46, 5082.

[8] Y. Ni, R. Rulkens, I. J. Manners, J. Am. Chem. Soc. 1996, 118, 4102.

[9] R. G. H. Lammertink, M. A. Hempenius, E. L. Thomas, G. J. Vancso, J. Polym. Sci., Part B: Polym. Phys. 1999, 37, 1009.

[10] W. Li, N. Sheller, M. D. Foster, D. Balaishis, I. Manners, B. Annis, J.-S. Lin, Polymer 2000, 41, 719.

[11] V. Bellas, M. Rehahn, Macromol. Rapid Commun. 2007, 28, 1415.

[12] J. A. Massey, K. Temple, L. Cao, Y. Rharbi, J. Raez, M. A. Winnik, I. J. Manners, J. Am. Chem. Soc. 2000, 122, 11577.

[13] J. Raez, I. Manners, M. A. J. Winnik, J. Am. Chem. Soc. 2002, 124, 10381.

[14] J. F. Gohy, B. G. G. Lohmeijer, A. Alexeev, X. S. Wang, I. Manners, M. A. Winnik, U. S. Schubert, Chem. Eur. J. 2004, 10, 4315.

[15] C. Kloninger, M. Rehahn, Macromolecules 2004, 37, 8319.

[16] C. Kloninger, M. Rehahn, Macromolecules 2004, 37, 1720.

[17] U. Datta, M. Rehahn, Macromol. Rapid Commun. 2004, 25 , 1615.

[18] Ch. Kloninger, D. Knecht, M. Rehahn, Polymer 2004, 45, 8323.

[19] Ch. Kloninger, M. Rehahn, Macromol. Chem. Phys. 2007, 28, 833.

[20] X. Wang, M. A. Winnik, I. Manners, Macromolecules 2005, 38, 1928.

[21] X. S. Wang, M. A. Winnik, I. Manners, Macromol. Rapid Commun. 2002, 23, 210.

[22] V. Bellas, M. Rehahn, Macromol. Chem. Phys. 2009, $210,320$.

[23] I. Manners, Science 2001, 294, 1664.

[24] R. G. H. Lammertink, M. A. Hempenius, I. Manners, G. Julius Vancso, Macromolecules 1998, 31, 795.

[25] R. G. H. Lammertink, M. A. Hempenius, G. J. Vancso, Langmuir 2000, 16, 6245

[26] V. S. Papkov, M. V. Gerasimov, I. I. Dubovik, S. Sharma, V. V. Dementiev, K. H. Pannell, Macromolecules 2000, 33, 7107.

[27] Polymer Handbook, J. Brandrup, E. H. Immergut, Eds., $3^{\text {rd }}$ edition, Wiley, New York 1989. 
[28] S. Z. D. Cheng, B. J. Wunderlich, J. Polym. Sci., Polym. Phys. Ed. 1986, 24, 577

[29] J. D. Hoffman, J. J. Weeks, J. Res. Natl. Bur. Stand. 1962, 66A, 13.

[30] K. Yamada, M. Hikosaka, A. Toda, S. Yamazaki, K. Tagashira, Macromolecules 2003, 36, 4802.

[31] G. Strobl, The Physics of Polymers, $2^{\text {nd }}$ edition, Springer, Berlin Heidelberg 1996.

[32] G. Strobl, Prog. Polym. Sci. 2006, 31, 398.

[33] H. Zhou, G. L. Wilkes, Polymer 1997, 38, 5735.

[34] H. B. Eitouni, N. P. Balsara, H. Hahn, J. A. Pople, M. A. Hempenius, Macromolecules 2002, 35, 7765.

[35] M. D. Whitmore, J. Noolandi, Macromolecules 1988, 21, 1482

[36] D. J. Blundell, A. Keller, A. J. Kovacs, J. Polym. Sci. B 1966, 481.

[37] A. Maus, E. Hempel, T. Thurn-Albrecht, K. Saalwächter, Eur. Phys. J. 2007, E 23, 91.

[38] A. T. Lorenzo, M. L. Arnal, J. J. Sanchez, A. J. Müller, J. Polym. Sci., Part B: Polym. Phys. 2006, 44, 1738.

[39] A. J. Müller, M. L. Arnal, Prog. Polym. Sci. 2005, 30, 559.

[40] J. Xu, Y. Ma, W. Hu, M. Rehahn, G. Reiter, Nat. Mater. 2009, 8 , 348.

[41] G. Strobl, Eur. Phys. J. E 2000, 3, 165.
[42] B. Heck, T. Hugel, M. Iijima, E. Sadiku, G. Strobl, New J. Phys. 1999, 1, 17.

[43] T.-Y. Cho, G. Strobl, Polymer 2006, 47, 1036.

[44] Y. Ni, R. Rulkens, I. J. Manners, J. Am. Chem. Soc. 1996, 118 , 4102.

[45] I. W. Hamley, The Physics of Block Copolymers, Oxford University Press, New York 1998.

[46] J. Bodycomb, D. Yamaguchi, T. Hashimoto, Macromolecules 2000, 33, 5187.

[47] A. P. Hammersley, ESRF Internal Report ESRF98HAo1T, FIT2D V9.129 Reference Manual V3.1 1998.

[48] H. B. Eitouni, N. P. Balsara, H. Hahn, J. A. Pople, M. A. Hempenius, Macromolecules 2002, 35, 7765.

[49] G. R. Strobl, M. Schneider, J. Polym. Sci., Polym. Phys. Ed. 1980 18, 1343.

[50] A. A. Minakov, D. A. Mordvintsev, C. Schick, Polymer 2004, 45, 3755.

[51] F. Zhang, B. Stühn, Colloid Polym. Sci. 2007, 285, 371.

[52] M. Al-Hussein, G. Strobl, Macromolecules 2002, 35, 1672.

[53] H. Marand, J. Xu, S. Srinivas, Macromolecules 1998, 31, 8219. 